\title{
Separation of butane isomers using a novel ZIF-8 slurry with extremely high efficiency: from laboratory study to industrial pilot test
}

\section{Mingke Yang}

China University of Petroleum, Beijing

\section{Huishan Wang}

China University of Petroleum, Beijing

Julian Y. Zuo

FMG Inc.

\section{Yu Han}

China University of Petroleum, Beijing

\section{Liya Chai}

China University of Petroleum, Beijing

Kun Li

China University of Petroleum, Beijing

\section{Wan Chen}

China University of Petroleum

\section{Xiaowan Peng}

China University of Petroleum, Beijing

\section{Baocan Dong}

China University of Petroleum, Beijing

\section{Chun Deng}

China University of Petroleum

\section{Chang-Yu Sun}

China University of Petroleum

Bei Liu

China University of Petroleum

Guang-Jin Chen ( $\nabla$ gjchen@cup.edu.cn )

China University of Petroleum, Beijing

\section{Article}

Keywords: Butane isomers, Separation, Efficiency, ZIF-8 slurry, Pilot test 
Posted Date: October 12th, 2021

DOl: https://doi.org/10.21203/rs.3.rs-941895/v1

License: (c) (i) This work is licensed under a Creative Commons Attribution 4.0 International License. Read Full License

Version of Record: A version of this preprint was published at Nature Communications on August 15th, 2022. See the published version at https://doi.org/10.1038/s41467-022-32418-6. 


\title{
Separation of butane isomers using a novel ZIF-8 slurry with extremely high efficiency: from laboratory study to industrial pilot test
}

Mingke Yang ${ }^{1}$, Huishan Wang ${ }^{1}$, Julian Y. Zuo ${ }^{2}$, Yu Han ${ }^{1}$, Liya Chai ${ }^{1}$, Kun $\mathrm{Li}^{1}$, Wan Chen ${ }^{1}$, Xiaowan Peng ${ }^{1}$, Baocan Dong ${ }^{1}$, Chun Deng ${ }^{1}$, Changyu Sun ${ }^{1 *}$, Bei Liu ${ }^{1}$, Guangjin Chen ${ }^{1 *}$.

${ }^{1}$ State Key Laboratory of Heavy Oil Processing, China University of Petroleum, Beijing 102249 , China

${ }^{2}$ FMG Inc., Edmonton, Alberta T6N 1M9, Canada

\begin{abstract}
Both n-butane and iso-butane are important petrochemical raw materials, and their separation is of great significance and full of challenge because of their close boiling characteristic. The ZIF-8 slurry formed with a novel mixed solvent M-water solution as sorption media was adopted to separate the mixture with high efficiency. The iso-/n-butane selectivity of ZIF-8/M-water slurries is as high as 890 with high kinetic performance, even transcending the upper limit of the new materials or membranes. More encouragingly, continuous pilot separation device was established and test results show that the purity and recovery ratio of iso-butane product achieved $99.46 \mathrm{~mol} \%$ and $87 \%$ respectively, which are remarkably superior to the corresponding performance ( $98.56 \mathrm{~mol} \%$ and $54 \%$ ) of the industrial distillation tower. To our best knowledge, this is the first industrial pilot test using MOFs for gas separation, and also an important step forward to the commercial application of MOFs in gas separation.
\end{abstract}

Key words: Butane isomers; Separation; Efficiency; ZIF-8 slurry; Pilot test

*To whom correspondence should be addressed. E-mail: cysun@cup.edu.cn (Chang-Yu Sun); gjchen@cup.edu.cn (Guang-Jin Chen). 


\section{Introduction}

Both n-butane and iso-butane are important petrochemical raw materials for direct application or synthesizing other petrochemicals. They usually co-exist in the liquefied petroleum gases produced in the condensation of natural gas or oil processing like fluid catalytic cracking (FCC). Hence, it becomes critical to separate butane isomers efficiently and economically. For example, high-purity iso-butane can be used ${ }^{1}$ for (1): reaction with olefins to produce alkylated high-octane gasoline, (2) co-oxidation with propylene to produce propylene oxide and co-produce tert-butanol, (3) dehydrogenation to produce iso-butene. On the other hand, n-butane can be used as refrigerant directly or for (1) oxidation to produce maleic anhydride ${ }^{2}$, (2) dehydrogenation to produce butadiene ${ }^{3}$. However, the separation of butane isomers is considered to be one of challenges in separation processes ${ }^{4,5}$, since their physical and chemical properties are close, such as the boiling point, vapor pressure, polarizability ${ }^{6}$. Up to now, the energy/cost-intensive distillation technique is still widely applied for butane isomers separation in the industry owing to the lack of more efficient alternatives.

The adsorption separation driven by inorganic porous materials, such as zeolite and activated carbon, is considered to be an attractive alternative to the present energy- and cost-intensive distillation-based separation, through selective size/shape exclusion ${ }^{7,8}$. For example, as the most extensively used separation agent in butane isomers separation, the MFI type zeolite (silicalite-1 and ZSM-5,) with $5.5 \AA$ multidimensional elliptical pores ${ }^{9}$ can distinguish n-butane from iso-butane. At present, the application of the MFI zeolite to membrane-based separation has been studied sufficiently $10,11,12,13$. The $\mathrm{n}$-/iso-butane selectivity of MFI membranes tested at $20^{\circ} \mathrm{C}-100^{\circ} \mathrm{C}$ ranges from 4 to $70^{5,12}$. In addition, Woo et al. ${ }^{14}$ prepared a MFI-based mixed matrix membrane to 
improve the n-butane permeability, while the highest n-butane/iso-butane separation factor was only 6.64. Besides the MFI-based membranes, Liu and co-workers ${ }^{15}$ synthesized face-centred cubic (fcu) type metal-organic framework (MOF) membrane on glassy polymer (6FDA-DAM) supports, exhibiting a n-butane/iso-butane separation factor of $\sim 30$ at $75^{\circ} \mathrm{C}$. Zhou et al..$^{5}$ reported high quality carbon molecular sieving membranes on $\gamma$-alumina substrates, the n-butane/iso-butane separation factor can reach 74. Nevertheless, even though many studies claim the strong performance of membrane-based separation technology in butane isomer separation, their commercial applications have not been seen yet in this field. The reasons are as follows: (1) membrane production is cumbersome and expensive ${ }^{15}$ and the membrane structure is prone to cracking $^{10}$. (2) The linear/branched isomer separation selectivity is low and the uptake capacity of adsorbents is $l^{10}{ }^{16}$. (3) The continuous multi-stage separation in membrane-based technology is difficult to be realized.

MOFs consisting of organic linkers coordinated to metal ions/clusters represent another important category of porous materials, which are very promising candidates with molecular sieve properties for gas separation $17,18,19,20$, due to the relatively easy and flexible tunability of their pore-aperture size and structure. Zeolitic imidazolate frameworks (ZIFs), as a subclass of MOFs, have attracted extensive attention in the field of gas separation in recent decades ${ }^{21,22}$, due to their excellent thermal and chemical stability and large surface area ${ }^{23}$. For example, the ZIF-8 framework $\left(\mathrm{Zn}(\mathrm{mIm})_{2}\right.$, mIm:2-methylimidazole), one of the most representative ZIFs, shows excellent performance in $\mathrm{CO}_{2}$ capture and light hydrocarbon separation ${ }^{24,25,26}$. It is worth mentioning adsorption separation includes two $\operatorname{modes}^{27}$ : (1) equilibrium separation, where one component has a higher equilibrium adsorption capacity than the other, and (2) kinetic separation, 
where one component has higher uptake rate than the other and selectivity is affected by the separation time. Zhang et al ${ }^{28}$ first reported that ZIF-8 exhibits great ideal kinetic selectivity $\left(2.5 \times 10^{6}\right)$ for $\mathrm{n}$-butane over iso-butane by estimating their thermodynamically corrected diffusivities. This value is much higher than the reported separation factors of zeolite-based membrane and MOF-based membrane, opening a gate for ZIF- 8 to separate butane isomers. Then, Zhang and co-workers ${ }^{29}$ successfully increased the n-butane diffusivity of ZIF-8 by post-synthetic thermal modification. However, as far as we know, there has been no experimental work reported on the direct separation of butane isomer mixtures using ZIF-8 in the literature. Therefore, the actual separation performance of ZIF-8 on the n-butane/iso-butane mixtures needs further investigation.

In addition, ZIFs, like other powdered porous materials, cannot be directly used for adsorption separation. Among a handful of emerging technologies, they are usually used in two ways. One is to apply ZIFs to a fixed-bed pressure swing adsorption (PSA) column after shaping-up, but this may significantly reduce the adsorption capacity and speed of the adsorbent ${ }^{30}$. Another way is to mix ZIFs with other materials, such as polymers, to form mixed matrix membrane for gas separation ${ }^{31}$. Hence, ZIFs have not been widely used for industrial gas separation up to now. In order to overcome various problems encountered in practical application of ZIFs and maintain their own excellent separation performance, our research group proposed a novel absorption-adsorption hybrid method (that is: the slurry method) for separating gas mixtures, e.g., $\mathrm{CO}_{2}$ capture, in which the ZIF-8 powder was suspended in a suitable solvent to form a fine slurry suspension ${ }^{32}$. Compared to conventional solid adsorption techniques suffering from the difficulty of heat integration in batch operation (e.g., fixed-bed PSA), the ZIF-8 slurry could flow 
like liquid absorbent and can be used in traditional sorption columns with a continuous multistage gas-slurry equilibrium separation process, achieving effective thermal integration. Li et al. ${ }^{33}$ successfully run the ZIF-8 slurry in a pilot-scale packed tower for $\mathrm{CO}_{2}$ capture and achieved good results in the aspects of separation efficiency, energy consumption, and stability during slurry operation. Pan et al. ${ }^{34}$, Liu et al. ${ }^{35}$, Chen et al. ${ }^{36}$,Yang et al. ${ }^{37}$ have applied this method to the separation of a series of low boiling gas mixtures like natural gases, FCC dry gases, coal bed gases, IGCC syngas etc. They all achieved promising results.

In this work, we applied the ZIF-8 slurry approach to the more challengeable separation of butane isomers. At first, it was found that an ideal solvent $\mathrm{M}$ with low toxicity, low volatility, low viscosity and high chemical stability met the needs of preparing the ZIF- 8 slurry for high efficient separation of butane isomers. Both single component sorption test and mixed isomer separation experiments demonstrated that solvent $\mathrm{M}$ could significantly increase the sorption speed of n-butane while water could drastically decline the sorption of iso-butane in the ZIF-8/M-water slurry. By optimizing the mass ratio of solvent $\mathrm{M}$ to water, both promising sorption speed of n-butane and selectivity ( $>890)$ of n-butane over iso-butane could be achieved. Subsequently, column breakthrough experiments were performed to further show the perfect kinetic separation performance of the slurry. More encouragingly, an industrial pilot apparatus was established to carry out continuous pilot separation tests, where feed gas was a multi-component butane mixture from a Chinese refinery. The pilot experiment was very successful; to our best knowledge, this is the first pilot experiment using MOFs for gas mixture separation in the world, and also an important step forward to commercial application of MOFs in gas mixture separation. 


\section{Results}

Determination of suitable solvent for preparing ZIF-8 slurry. We first tested the adsorption behavior of the ZIF-8 powder and the ZIF-8/water slurry for n-butane and iso-butane. As predicted by Zhang et $\mathrm{a}^{28}$, our experimental results illustrated in Fig.1 indicate very high kinetic selectivity of the ZIF-8 powder or the ZIF-8/water slurry for n-butane over iso-butane. The uptake of iso-butane keeps very low for a long time while that of n-butane increases continuously with elapsed time until equilibrium is reached. This is because the $-\mathrm{CH}_{3}$ branch in an iso-butane molecule resists itself to enter the cages of ZIF-8. However, the adsorption speed of the ZIF-8 powder for n-butane is not high enough for a practical adsorption separation process although its maximum equilibrium uptake ( $4.0 \mathrm{mmol} / \mathrm{g}$ or so. Fig. 2(a)) shows the n-butane sorption capacity is significantly higher than the most values of other adsorption materials reported in the literature, e.g., TIFSIX-3Ni $(1.13 \mathrm{mmol} / \mathrm{g}$ at $298 \mathrm{~K})$ and $\mathrm{ZU}-36-\mathrm{CO}(2.2 \mathrm{mmol} / \mathrm{g} \text { at } 298 \mathrm{~K})^{16}$, Y-fum-fcu-MOFs $(2.0 \mathrm{mmol} / \mathrm{g} \text { at } 293 \mathrm{~K})^{38}$, CMS-PMOF-1 $(1.9 \mathrm{mmol} / \mathrm{g} \text { at } 293 \mathrm{~K})^{39}$, ana-ZMOF $(0.9 \mathrm{mmol} / \mathrm{g} \text { at } 293 \mathrm{~K})^{6}$, and commercial shaped MFI zeolite including ZSM-5 $(1.1 \mathrm{mmol} / \mathrm{g}$ at 300 $\mathrm{K})^{40}$ and silicalite-1 $(1.7 \mathrm{mmol} / \mathrm{g} \text { at } 298 \mathrm{~K})^{12}$. The n-butane sorption capacity further becomes lower when the ZIF-8 powder was shaped for practical PSA or TSA operation (Supplementary Fig. 2). The sorption speed of n-butane in the ZIF-8/water slurry is even lower than that in the solid ZIF-8. Hence, search for a new ZIF-8 slurry is required. 


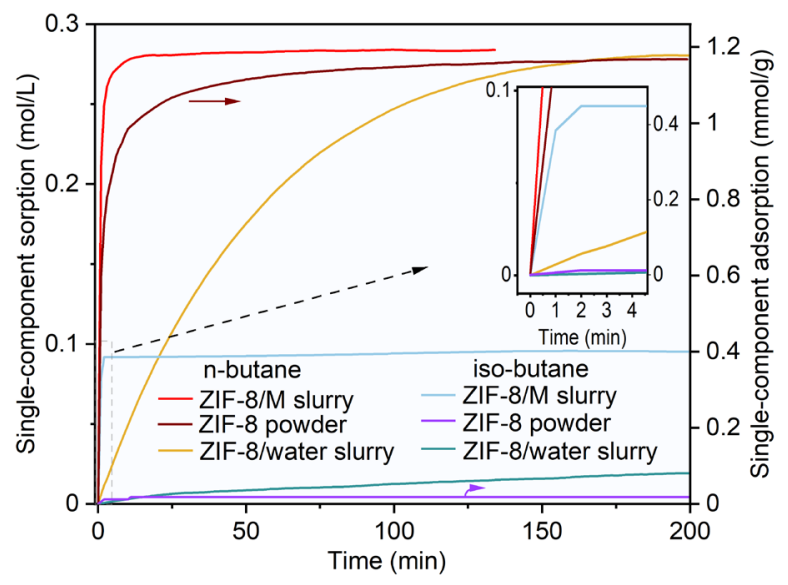

Fig. 1 Comparison of the sorption kinetics of single-component in different media. Kinetic profiles of n-butane and iso-butane on ZIF-8 powder (right axis), ZIF-8(35wt\%)/M slurry and ZIF-8(25wt\%)/water slurry (left axis) at 293.15K and an initial gas-slurry volume ratio of about 6.8 (initial gas-solid volume ratio of about 26.7 for ZIF-8 powder). The profiles were obtained via P-T curves shown in Supplementary Fig. 1.

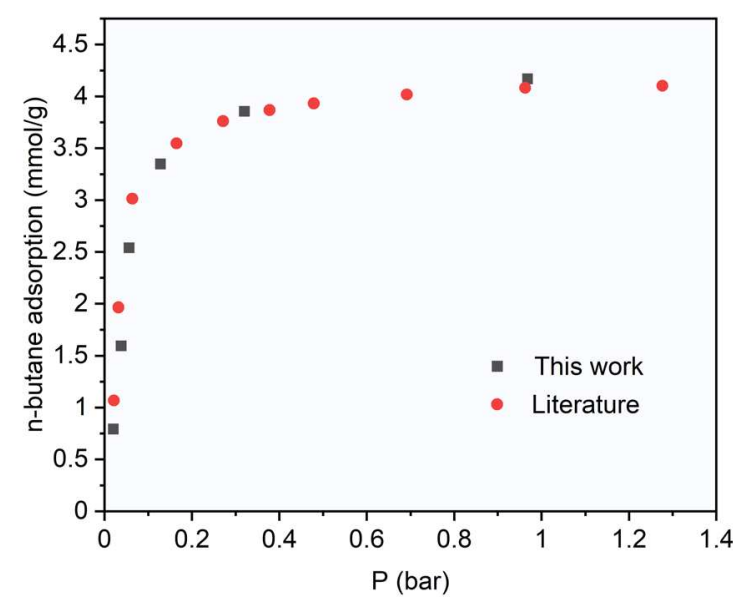

(a)

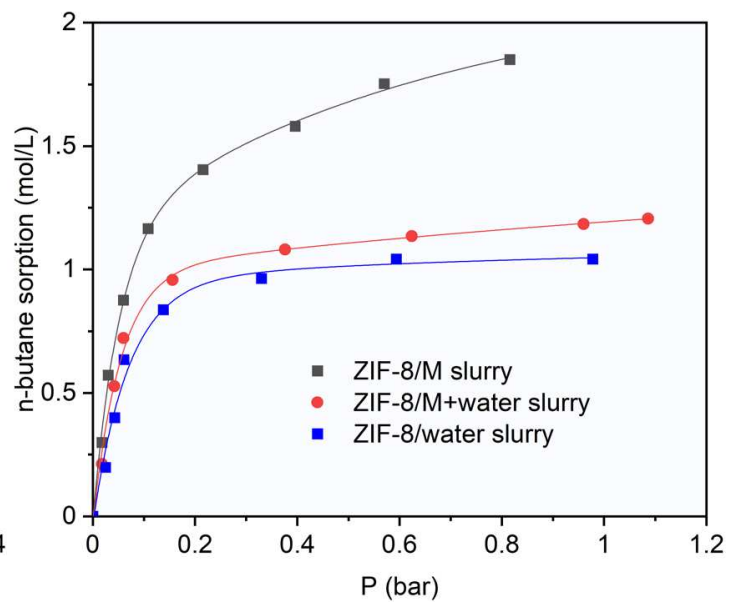

b)

Fig. 2 n-butane sorption capacity. Sorption isotherms of n-butane on (a): ZIF-8 powder at 293.15 K measured in this work and the literature ${ }^{27}$, (b): ZIF-8 (35wt\%)/M slurry, ZIF-8 (25wt\%)/water slurry and ZIF-8 (30wt\%) slurry with solvent composition of $80 \mathrm{wt} \% \mathrm{M}+20 \mathrm{wt} \%$ water at $293.15 \mathrm{~K}$. The lines are guides for eyes.

The sorption behavior of the ZIF-8 slurry strongly depends on the solvent chosen for preparation. The criteria for choosing a suitable solvent are: (1) its molecules could not enter the pores of ZIF-8, otherwise adsorption capacity of ZIF-8 will be lost; (2) The solubility of 
iso-butane in it should be as low as possible, otherwise the apparent selectivity of the ZIF- 8 slurry will be lowered significantly compared with the solid ZIF-8, hence it should be hydrophilic; (3) it should be highly chemical stable when mixed with ZIF-8, low viscosity and volatility; (4) it could accelerate the adsorption of n-butane in suspended ZIF-8; (5) serious foaming does not occur during the desorption process. Through a great of sieving and testing work based on the above criteria, it is found that solvent $\mathrm{M}$ almost meets all the requirements aforementioned: much higher sorption speed of the ZIF-8/M slurry than that of the solid ZIF-8 as shown in Fig. 1, high normal boiling temperature, high chemical stability, lower viscosity, no foaming during a desorption process, although there is certain solubility of iso-butane in it. Fortunately, when adding certain quantity of water to solvent $\mathrm{M}$, the solubility of iso-butane decreases drastically, the higher water concentration, the lower solubility of iso-butane, as shown in Supplementary Fig. 4. Correspondingly, the sorption capacity for iso-butane in the ZIF-8/M slurry could be drastically decreased when adding more than $20 \mathrm{wt} \%$ water in solution as shown in Fig. 3b, indicating a high selectivity of n-butane over iso-butane because the sorption capacity of n-butane does not decrease significantly with the addition of water as seen from Fig. 3a, where the profiles were obtained from the measured P-T curves shown in Supplementary Fig. 2 and Supplementary Fig. 3, respectively. More importantly, Fig. 3c shows that, when water content in the solution is smaller than $40 \mathrm{wt} \%$, the overall sorption speed of n-butane in the slurry retains slightly higher than that in the ZIF-8 powder but significantly higher than that in a shaped ZIF-8. It should be noted that the sorption speed in a flowable slurry could be further increased by applying mechanical enhancing measures such as stronger stirring, fine distribution of gas in slurry or vise versa. At the same time, the n-butane sorption capacity in the ZIF-8 (30 wt\%) slurry with solvent composition of $80 \mathrm{wt} \%$ 

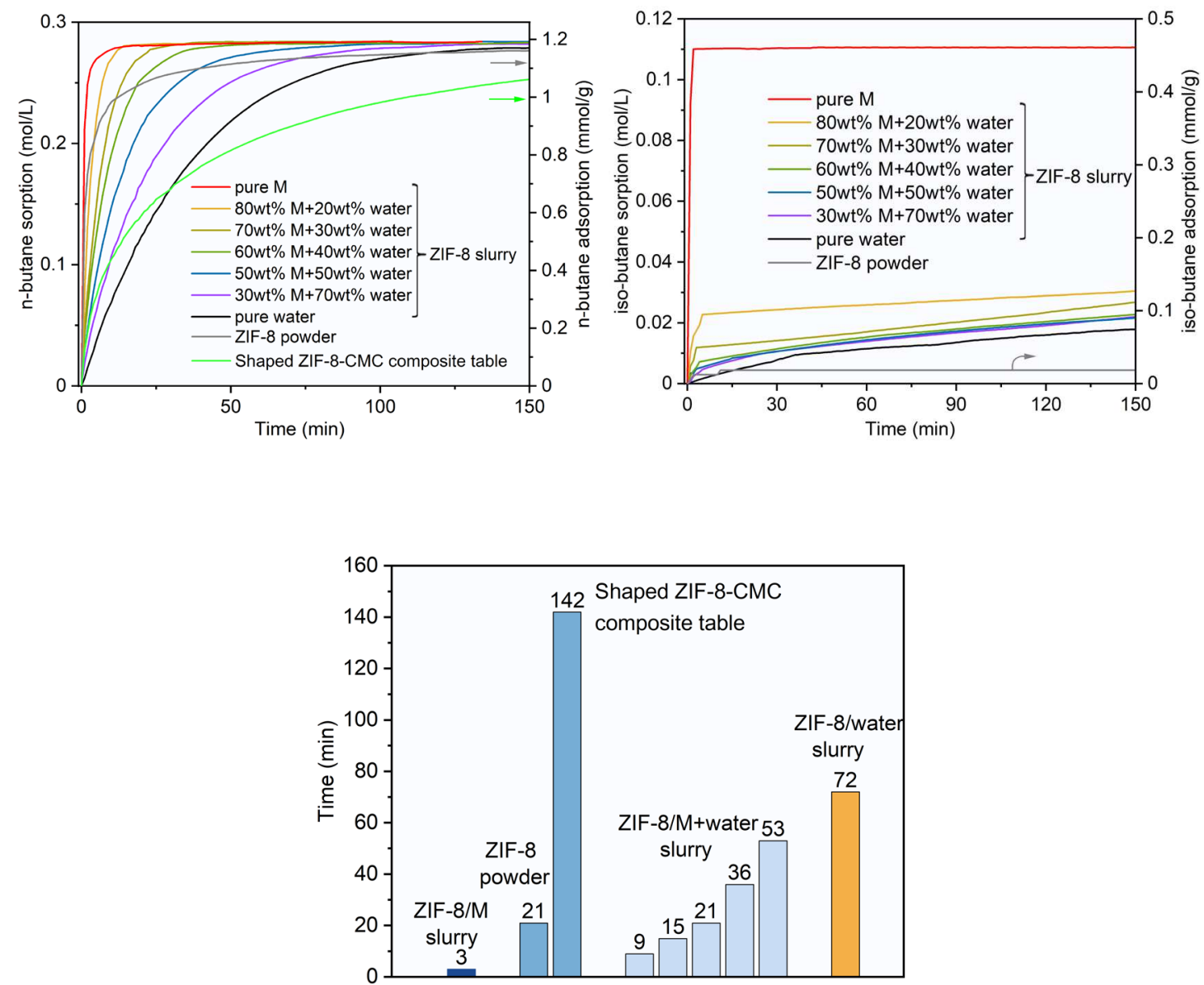

$\begin{array}{lll}\text { (a) } & \text { (b) (c) } & \text { (d) (e) (f) (g) (h) }\end{array}$

(c)

Fig. 3 Comparison of the single-component sorption speed of solid ZIF-8 and ZIF-8 slurries. Kinetic profiles of n-butane (a) and iso-butane (b) in ZIF-8 slurries (left axis) and ZIF-8 powder, shaped ZIF-8 (right axis), where temperature, initial gas-slurry volume ratio, initial gas-solid volume ratio and solid ZIF-8 content in the slurries were set to $293.15 \mathrm{~K}, \sim 6.8, \sim 26.7$ and $30 \mathrm{wt} \%$ respectively. CMC: Carboxymethyl Cellulose Sodium; (c) comparison of times for different sorption media to reach $90 \%$ of the equilibrium sorption capacity of n-butane, where "d" to "h" on the abscissa correspond to $20 \mathrm{wt} \%$ to $70 \mathrm{wt} \%$ of the water content in the solvent. 


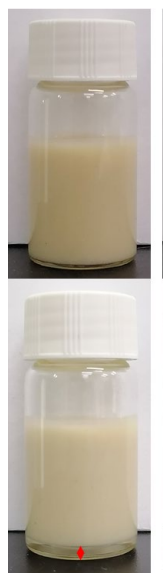

(a)

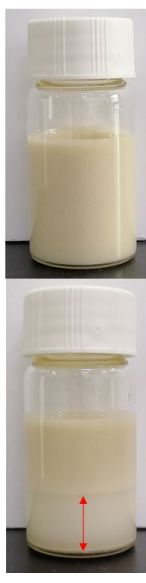

(b)

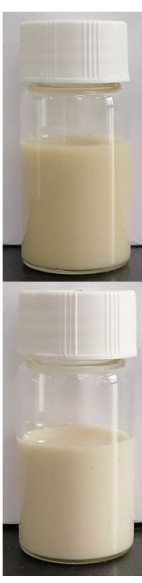

(c)

Fig. 4 The stability of ZIF-8 slurries. State changes of ZIF-8 (30 wt\%) slurry with different liquid media over 24 hours: (a) water, (b) solvent M, (c) solvent M (80 wt $\%)+$ water $(20 \mathrm{wt} \%)$.

Separation of iso/n-butane mixture by using ZIF-8 slurries. After determining the suitable solvent for preparing ZIF-8 slurry, a series experiments with respect to the separation of gaseous iso-/n-butane mixtures were performed. The experimental results are tabulated in Supplementary Table 1 to 3, in which the pressure $P_{\mathrm{e}}$, the compositions of gas phase and slurry (expressed with the dry-basis mole fraction of n-butane $y_{1}, x_{1}$ respectively), the selectivity of n-butane over iso-butane were determined when the gas-slurry contacting system becomes stable, that is marked by the system pressure decay of no more than 5 mbar within 30 minutes. Supplementary Table 1 shows a comparison of the separation abilities of the solid ZIF-8 powder and the ZIF-8 slurries with different solvent compositions. As expected above, the ZIF-8 powder exhibits an extremely high selectivity, 11757, for n-butane over iso-butane. Although the selectivity of the ZIF-8/water, 577, is still high enough, it is much lower than that of the solid ZIF-8 powder because it seems that iso-butane is easier to enter the pores of ZIF-8 in the state of the slurry as indicated by Fig. $\mathbf{1}$. Compared with the ZIF-8/water slurry, the ZIF-8/M slurry gives a bigger decrease in the separation selectivity; it becomes only 113 because the solubility of iso-butane in solvent $\mathrm{M}$ is 
much higher than that in water. However, 113 has been still higher than all reported values of the other separation media up to now, as shown in Fig. 5. Considering the high sorption speed of n-butane in the ZIF-8/M slurry and multi-stage separation in an absorption column is easy to realize, 113 is already high enough for an actual application.

Interestingly, the separation selectivity of the ZIF-8/M-water is extremely higher than those of both the ZIF-8/water slurry and the ZIF-8/M slurry; it ranges from 890 to 2985 when water content in the mixed solvent changes from $20 \mathrm{wt} \%$ to $70 \mathrm{wt} \%$. More than $\sim 98 \%$ of n-butane could be removed from the gas phase after a single stage of separation in all the five experiment runs, the mole fraction in the gas phase decreased from $38.2 \mathrm{~mol} \%$ to $1.35 \mathrm{~mol} \%$ or so only. These results are all encouraging indeed. Taking both sorption speed and separation factor into account, we recommend the most suitable water content in the mixed solvent is $20-30 \mathrm{wt} \%$, and in the subsequent experiments, it is mainly set to $20 \mathrm{wt} \%$, except for the regeneration experiment.

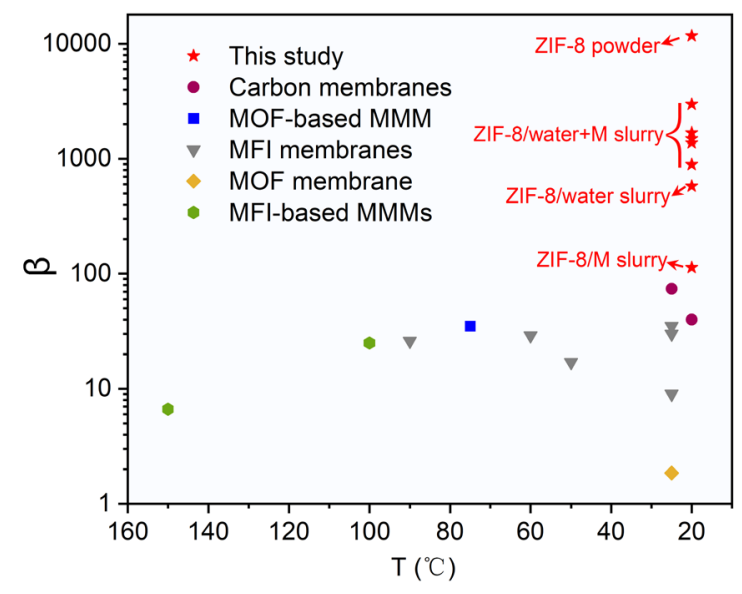

Fig. 5 Separation performance of ZIF-8 powder and ZIF-8 slurries compared to top-performing materials.

Comparison of the n-/iso-butane separation factor $(\beta)$ of ZIF-8 powder and ZIF-8 slurries with various membranes reported in literatures. (Carbon memabranes ${ }^{5,41}$; MOF-based mixed matrix membrane ${ }^{15}$; MFI membranes ${ }^{12,42,43,44,45,46}$, MOF membrane ${ }^{47}$ and MFI-based mixed matrix membrane ${ }^{1448}$ )

Perfect regeneration performance is critical for the practical application of a sorbent. Hence, 
the regeneration performance of one ZIF-8/M-water slurry with a solid content of $30 \mathrm{wt} \%$ and solvent composition of $70 \mathrm{wt} \%$ solvent $\mathrm{M}+30 \mathrm{wt} \%$ water was tested. In all the experimental runs, the n-butane rich slurry was regenerated by vacuuming at $323.15 \mathrm{~K}$ for 20 minutes. This regeneration conditions should be very mild. The experimental results are listed in Supplementary Table 2. One can see that during the 22 cycles in 14 days, the separation performance of the slurry approximately remains stable although there is a little fluctuation because feed gas compositions were not fixed perfectly; no declination tendency was observed. In addition, the XRD diffraction pattern of the ZIF-8 powder recovered after this sorption-desorption cycle experiment is completely consistent with that of fresh ZIF-8 (Supplementary Fig. 5), suggesting the structural integrity of the recovered ZIF-8. The above results indicate the slurry is of perfect regeneration. In these group of experiments, the concentration of iso-butane in feed gas was control to $90 \mathrm{~mol} \%$ or so. One can see that high purity of iso-butane ( $>99.6 \mathrm{~mol} \%$ ) could be achieved in the gas phase after one stage of separation. The separation results of the slurry under different desorption conditions are listed in Supplementary Table 3.

\section{Column breakthrough test and pilot scale continuous separation experiment. Column} breakthrough test is an effective tool to evaluate the kinetic separation performance of sorbents, which can describe the sorption separation process more accurately and evaluate the possibility of the sorbents in the actual industrial application process. Herein, a column [filled with $1800 \mathrm{~g}$ ZIF-8(30wt\%)/M-water slurry] breakthrough test using the n-/iso-butane (41 mol\%/59 mol\%) gas mixture was carried out at $303.15 \mathrm{~K}$ and 2 bar. As anticipated, excellent separation performance was achieved on the slurry column. As shown in Fig. 6 and Supplementary Table 4, iso-butane 
breakthrough the column within $10 \mathrm{~min}$ and quickly reached $90 \mathrm{~mol} \%$ within $1.33 \mathrm{~h}$, confirming that the ZIF-8/M-water slurry can efficiently exclude iso-butane. In contrast, the n-butane concentration can remain low for a long time. If He is not counted, the obtained purity of iso-butane in the outlet gas can be maintained at $99+\operatorname{mol} \%$ for $4.83 \mathrm{~h}$, even after $9.92 \mathrm{~h}$, the iso-butane concentration in the outlet gas is still higher than $90 \mathrm{~mol} \%$. It is worth indicating that the slurry used in these group of experiments has been used 7 times in 30 days, under the regeneration condition of He purge at $353.15 \mathrm{~K}$ and atmospheric pressure. The breakthrough test verified the excellent kinetic performance and molecular exclusion effect of the ZIF-8/M-water slurry.

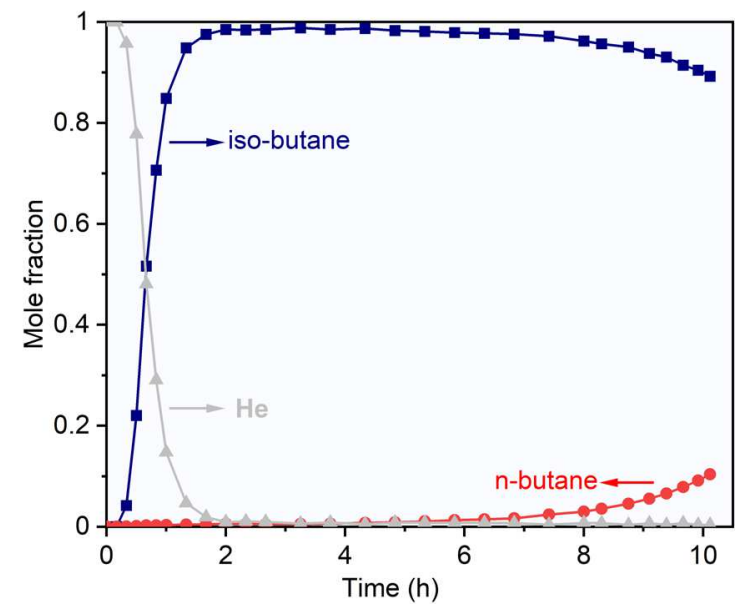

Fig. 6 Gas mixture column breakthrough results. Column breakthrough curve for a n-butane(1)/iso-butane(2) gas mixture $\left(z_{2}=59 \mathrm{~mol} \%\right)$ using ZIF-8(30wt\%)/M-water slurry at $303.15 \mathrm{~K}$ and 2 bar. (Gas flow rate: 60 $\mathrm{mL} / \mathrm{min})$ 


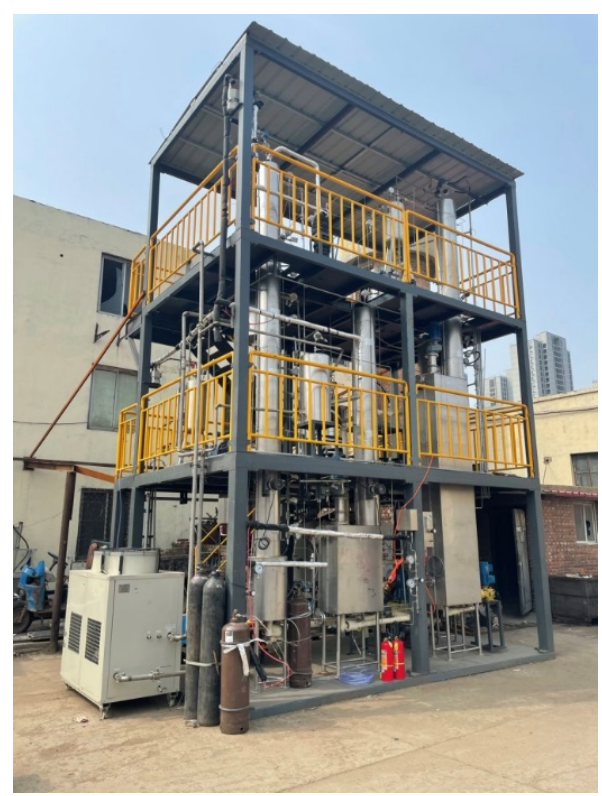

Fig. 7 The physical picture of the pilot plant for continuous C4 gas mixture sorption-desorption separation experiment.

Furthermore, a C4 continuous separation pilot plant (Fig. 7) was set up to verify the feasibility of the scale-up slurry separation process. The functional department of the pilot plant is a sorption column $(5.17 \mathrm{~m})$ and a desorption column $(5.48 \mathrm{~m})$, both of them are placed with CY700 structured packing. We chose a typical multi-component C4 gas mixture taken from a Chinese refinery as the feed gas. From the perspective of ensuring the smooth flow of the slurry, we conservatively set the ZIF-8 content in the slurry to $20 \mathrm{wt} \%$, because the lower the ZIF-8 content, the lower the slurry viscosity. The entire system was charged with $25 \mathrm{~kg}$ ZIF-8(20wt\%)/M-water slurry. Especially noteworthy is that the ZIF-8 material used in the pilot plant was prepared by ourselves in large quantities using a novel, low-cost, rapid, and high-yield method on a pilot scale ${ }^{49}$. The test results are very encouraging; a group of representative results and corresponding operation conditions are shown in Table 1. As seen, the iso-butane concentration is effectively enriched from $46.33 \mathrm{~mol} \%$ in the feed gas to $99.46 \mathrm{~mol} \%$ in the product gas, while it is $12.17 \mathrm{~mol} \%$ in the desorbed gas. After calculation, the recovery ratio of 
iso-butane $\left(R_{\text {iso-butane }}\right)$ and total separation factor $(\beta)$ (iso-butane over all other components) reached $87 \%$ and 1329 , respectively. For comparison, the separation results obtained by the Chinese refinery using the distillation method with similar feed gas composition are also shown in Table 1. As seen, the iso-butane purity in the top gas is only $98.56 \mathrm{~mol} \%$, less than $99.46 \mathrm{~mol} \%$ of the slurry method. On the other hand, the iso-butane concentration in the bottom product is as high as $36.04 \%$, resulting in a significant reduction in the iso-butane yield ( $R_{\text {iso-butane }}: 54 \%$ ). Additionally, the height and tray number of the distillation column are $72 \mathrm{~m}$ and 120 , respectively, to meet the separation requirements. In this case, equipment investment is expensive. At the same time, the reflux ratio of the distillation column is set to $>10$, leading to high energy cost, while there is no reflux in the slurry method. In summary, the slurry method will bring a great improvement in separation efficiency, energy cost and equipment investment over the traditional distillation method.

The excellent stability of the slurry as an adsorbent can also be guaranteed, because the slurry used in this group of experiment has been investigated in the pilot plant for more than 7 months in a flowing or static way, spanning a temperature range of $-10^{\circ} \mathrm{C}$ to $70{ }^{\circ} \mathrm{C}$. At the same time, the uniform state of the recovered slurry (Supplementary Fig. 6c) and the XRD analysis results of the recovered ZIF-8 powder (Supplementary Fig. 6a) also confirmed the structural integrity of ZIF-8 and the compatibility of ZIF-8 with solvent. These results are consistent with the previous laboratory results. After the experiment, we took out a piece of packing from the sorption column after washing with water. As shown in Supplementary Fig. 6b, there is no slurry blockage and corrosion on the surface and inside of the stainless steel structured packing, which means that the slurry containing the solid phase can be used in the packed column for gas separation. The pilot 
test results provide powerful data support for the further industrial application of the porous slurry.

Table 1 Operating conditions of the pilot plant and a comparison of the separation results between the pilot

plant and a Chinese refinery using distillation method for the $\mathrm{C} 4$ mixtures with similar composition.

\begin{tabular}{|c|c|c|c|c|c|c|c|c|c|}
\hline \multirow{2}{*}{\multicolumn{2}{|c|}{$\begin{array}{l}\text { Operating } \\
\text { conditions }\end{array}$}} & \multirow{2}{*}{\multicolumn{2}{|c|}{$\begin{array}{l}\text { Sorption column } \\
30 \sim{ }^{\circ} \mathrm{C} / 2 \text { bar }\end{array}$}} & \multirow{2}{*}{\multicolumn{2}{|c|}{$\frac{\text { Desorption column }}{60 \sim^{\circ} \mathrm{C} / 0.1 \text { bar }}$}} & \multirow{2}{*}{\multicolumn{2}{|c|}{$\frac{\text { Slurry flow rate }}{12 \mathrm{~L} / \mathrm{h}}$}} & \multirow{2}{*}{\multicolumn{2}{|c|}{ Gas flow rate }} \\
\hline & & & & & & & & & \\
\hline & & $\begin{array}{l}\text { iso- } \\
\text { butane }\end{array}$ & $\begin{array}{c}\text { n- } \\
\text { butane }\end{array}$ & $\begin{array}{l}\text { trans-2- } \\
\text { butene }\end{array}$ & $\begin{array}{c}1- \\
\text { butene }\end{array}$ & $\begin{array}{c}\text { iso- } \\
\text { butylene }\end{array}$ & $\begin{array}{l}\text { cis-2- } \\
\text { butene }\end{array}$ & $\begin{array}{c}\text { 1,3-buta } \\
\text { iene }\end{array}$ & \\
\hline \multirow{3}{*}{$\begin{array}{l}\text { Pilot } \\
\text { plant }\end{array}$} & $\begin{array}{c}\text { Feed gas } \\
(\mathrm{mol} \%)\end{array}$ & 51.19 & 13.47 & 11.96 & 16.33 & 0.08 & 6.85 & 0.12 & \multirow{3}{*}{$\begin{array}{c}\mathbf{R}_{\text {iso-butane }} \\
\mathbf{8 7 \%} \\
\beta: 1329\end{array}$} \\
\hline & $\begin{array}{l}\text { Product gas } \\
\text { (mol\%) }\end{array}$ & 99.46 & 0.32 & 0.03 & 0.13 & 0.02 & 0.04 & 0 & \\
\hline & $\begin{array}{c}\text { Desorbed gas } \\
\text { (mol\%) }\end{array}$ & 12.17 & 24.62 & 18.92 & 31.21 & 0.15 & 12.70 & 0.23 & \\
\hline \multirow{3}{*}{$\begin{array}{l}\text { Distil- } \\
\text { lation }\end{array}$} & $\begin{array}{l}\text { Feed gas } \\
(\mathrm{mol} \%)\end{array}$ & 54.59 & 12.78 & 7.61 & 14.43 & 0.13 & 10.37 & 0.09 & \multirow{3}{*}{$\begin{array}{c}\mathbf{R}_{\text {iso-butane }} \\
\mathbf{5 4 \%}\end{array}$} \\
\hline & $\begin{array}{l}\text { Top product } \\
\text { (mol\%) }\end{array}$ & 98.56 & 0 & 0 & 1.31 & 0.03 & 0 & 0.10 & \\
\hline & $\begin{array}{c}\text { Bottom product } \\
\text { (mol\%) }\end{array}$ & 36.04 & 18.07 & 11.29 & 18.28 & 0.16 & 16.14 & 0.08 & \\
\hline
\end{tabular}

\section{Discussion}

Traditional adsorption-based gas separation techniques such as pressure (vacuum) swing adsorption $(\mathrm{P}(\mathrm{V}) \mathrm{SA})$, temperature swing adsorption (TSA) are more energy efficient than distillation for butane isomer separation. However, these techniques have their inherent drawbacks. For example, there will inevitably be crushing of adsorbents and pressure loss inside the adsorption column ${ }^{50}$. And the shaped non-fluid solid phase adsorbents are typically used in the fixed-bed, which is a batch process with low efficiency. The slurry approach proposed in this work is a potential solution to these problems by fluidizing solid-phase adsorbent. On the other hand, the higher n-butane uptake on ZIF-8 at lower pressure as shown in Fig. 2(a) and the high n-butane desorption heat $\left(\sim 20-32 \mathrm{~kJ} / \mathrm{mol}^{27}\right)$ indicates that a TSA but not a PSA technique should be adopted when using ZIF-8 as an adsorbent. The heat transfer and heat integration will then be a 
challenging issue for a fixed-bed as heat conductivity is low for a porous media. The slurry approach will become hopeful in this case because cooling and heating of the slurry could be easily carried out because it could flow like fluid. At the same time, the vaporization of solvent water with low boiling point in the desorption process will enhance the degassing efficiency due to the stripping effect of water vapor.

ZIF-8 has superior properties in terms of n-butane uptake and n-/iso-butane selectivity. A carefully chosen ZIF-8/M combination leads to a significantly enhanced sorption speed, but an increase in the sorption of iso-butane, thereby reducing the overall selectivity. The further proposed solvent M-water mixed-based slurry with satisfactory sorption speed solves this problem by reducing the solubility of iso-butane. Theoretically, the solid ZIF-8 should have the highest sorption speed due to the smallest mass transfer resistance, but in fact it is not the case. The faster sorption speed of the slurry is attributed to the dispersing effect of solvent M on ZIF-8, which can be proved by some experimental evidences. First, the kinetic curves of the fresh and regenerated ZIF-8(30 wt\%)/M-water slurry (Supplementary Fig. 7a) show that the regenerated slurry has a faster sorption speed, which should not happen if the properties of the slurry do not change. In order to confirm the dispersion state of ZIF-8 in the slurry, we measured the particle size of ZIF-8 in different slurries. As shown in Supplementary Fig. 7b, the average particle sizes of the fresh ZIF-8/M slurry and the regenerated ZIF-8/M-water slurry are $\sim 2.2 \mu \mathrm{m}$ and $\sim 1.18 \mu \mathrm{m}$, respectively, while those of the fresh or regenerated ZIF-8/water slurry and fresh ZIF/M-water slurry exceed the upper limit $(6 \mu \mathrm{m})$ of the measuring apparatus, confirming the good dispersibility of solvent $\mathrm{M}$ to ZIF-8 particles. The SEM images of the fresh and recovered ZIF-8 from the ZIF-8/M-water slurry visually show the difference in their surface morphology (Supplementary Fig. 8). The 
agglomeration of ZIF-8 particles has been significantly inhibited by solvent M. The agglomeration of ZIF-8 nanoparticles, which is prone to occurring due to its high surface energy, impose a certain negative effect on the sorption speed by increasing the mass transfer resistance. This also explains why the sorption speed of the solid ZIF-8 is reduced after shaping. In this case, the slurry method has more potential advantage than the fixed bed process, because the kinetic performance of the slurry will gradually improve over time.

It is very interesting that the separation ability of the ZIF-8/M-water slurry is greater than that of the ZIF-8/water slurry and the ZIF-8/M slurry. Mixing of water and solvent $\mathrm{M}$ originates significant synergic effect, we guess the mechanism for this synergic effect lies in two aspects. At first, for the ZIF-8/water slurry, the addition of solvent $\mathrm{M}$ increases the sorption speed of n-butane; the fast pre-filling of n-butane molecules in the pores of ZIF-8 inhibits the following adsorption of iso-butane molecules ${ }^{14}$ because it is a very slow process even for pure iso-butane as demonstrated by Fig. 3b. The pressure profiles plotted in Supplementary Fig. 9 also support this mechanism, there is not an obvious and continuous declining tendency in the ZIF-8/M-water slurry as depicted in Supplementary Fig. 3b for pure iso-butane in the ZIF-8/water or the ZIF-8/M-water slurry after a certain time period, when n-butane sorption reaches equilibrium. Secondly, for the ZIF-8/M slurry, the addition of water dramatically decreases the solubility of iso-butane in solvent and then raises the apparent selectivity of the slurry for n-butane over iso-butane. In fact, this effect could be expected from the single gas sorption experimental results shown in Fig. 3. The suitable water content in mixed solvent should be $20-30 \mathrm{wt} \%$, where both high sorption selectivity and high sorption speed could be achieved; they are seriously required in an actual industrial application. It should be also noted that, in the regeneration experiment where the n-butane concentration in feed 
gas is only $\sim 10 \mathrm{~mol} \%$, the separation selectivities (see Supplementary Table 2) are remarkably lower than those listed in Supplementary Table 1 where the concentration of n-butane in the feed gas is $38.2 \mathrm{~mol} \%$. This phenomenon is consistent with mechanism stated above for the synergic effect of water and solvent M. When mole fraction of n-butane in the gas phase is lower, its occupancy percentage in the ZIF-8 pores will be lower too. As a result, the inhibition effect on the adsorption of iso-butane caused by the pre-adsorption of n-butane will become weaker. Next, we intentionally increased the n-butane concentration in the feed gas to $71.85 \mathrm{~mol} \%$ to verify this effect. As expected, the separation selectivity reached the highest 2987 (Supplementary Table 5).

Overall, the excellent selectivity for n-butane over iso-butane, in combination with the high sorption capacity and high sorption speed of n-butane, makes the slurry approach proposed in this study suitable for a promising candidate for the challenging separation of butane isomers.

\section{Methods}

Materials. Analytical grade solvent M, Carboxymethyl Cellulose Sodium (CMC), Hydroxyethyl Cellulose (HEC) were purchased from the Shanghai Aladdin BioChem Technology Co., Ltd. Tap water was used. n-butane (99.5\%), iso-butane (99.5\%) were purchased from the Beijing HaiPu Gases Industry Co., Ltd. and used to prepare n-/iso-butane feed gas mixtures with different compositions. ZIF-8 was synthesized by our laboratory ${ }^{49}$.

Sorption measurements. In this work, the measurements of gas-slurry(solid) phase equilibrium and kinetics, as well as mixed gases separation of different systems were conducted in the equipment apparatus as shown in Supplementary Fig. 10. As shown in our previous reports ${ }^{32,37}$, there are two main components, a stainless steel blind cell with $132.4 \mathrm{~cm}^{3}$ effective volume 
(including the connected pipeline) and a transparent sapphire cell with $59.9 \mathrm{~cm}^{3}$ effective volume (including the connected pipeline), both are installed in a constant temperature air bath to keep the uniform temperature. The maximum working pressure of two cells are designed to be $20 \mathrm{MPa}$. The temperature and pressure of the system are measured by the secondary platinum resistance thermometer (type-pt100) and the differential pressure transducer, with uncertainties of $\pm 0.1 \mathrm{~K}$ and $\pm 0.002 \mathrm{MPa}$, respectively. A LG100H luminescence source is installed in the air bath so that the phenomenon in the transparent sapphire cell can be observed more clearly. Real-time readings of the pressure and temperature are automatically recorded by a computer. Additionally, the composition of n-/iso-butane mixtures are analyzed by a Hewlett-Packard Gas Chromatography (HP 7890).

Before each experiment, the sapphire cell is taken out from the apparatus, thoroughly cleaned up with tap water and dried. Given quantities of the solid-phase ZIF-8 or ZIF-8 slurry are weighed and added to the sapphire cell. The mixture of the solid-phase ZIF-8 and liquid solvent are stirred to form fine slurry. Subsequently, the cell is reinstalled to the air bath and fixed. The whole system (blind cell + sapphire cell + the connected pipeline) is evacuated to remove air, then the feed gas with sufficiently high pressure is injected into the blind cell through the gas cylinder. The air bath is powered on after setting the temperature to a given value. Once both temperature and pressure of the blind cell are stable for one hour, the real-time pressure of gas in the blind cell is recorded as $P_{0}^{b}$. Then, the top valve of the sapphire cell is slowly opened, letting the feed gas flow into the sapphire cell until the desired pressure value $\left(P_{0}\right)$ is reached, and the magnetic stirring with a fixed rate is turned on to promote gas-slurry mass transfer. When the system pressure remains stable for 1h (for gas-liquid equilibrium sorption) or the separation reaches the set time (for non-equilibrium 
kinetic separation), the magnetic stirring is turned off, and the pressures of the blind cell and the sapphire cell are recorded as $P_{1}^{b}$ and $P_{\mathrm{E}}$, respectively. For the separation experiment of mixed gases, the n-/iso-butane mixture after sorption separation in the sapphire cell is sampled with constant pressure by pushing the hand pump continuously and analyzed by using the HP 7890 gas chromatograph.

In this work, the uptake of each gas species in the slurry (or ZIF-8 powder) is calculated based on the mass balance as follows.

The total moles of the feed gas injected into the sapphire cell $\left(n_{t}\right)$ from the blind cell is calculated by the following equation

$$
n_{t}=\frac{P_{0}^{b} \times V_{b}}{Z_{0} \times R \times T}-\frac{P_{1}^{b} V_{b}}{Z_{1} \times R \times T}
$$

where $P_{0}^{b}$ and $P_{1}^{b}$ are the pressures of the blind cell before and after injecting the gas into the sapphire cell, respectively, $V_{b}$ is the total volume of the blind cell together with the connected pipeline, $T$ and $R$ are the system temperature and the universal gas constant, respectively, compressibility factors $Z_{0}$ and $Z_{1}$ are calculated by the BWRS equation of state at $P_{0}^{b}$ and $P_{1}^{b}$.

The moles of gas remained in the gas phase of the sapphire cell after sorption process is determined by:

$$
n_{E}=\frac{P_{E} \times V_{g}}{Z_{E} \times R \times T}
$$

where $P_{E}, V_{g}$ and $Z_{E}$ are the pressure, the volume and the compressibility factor of the gas phase in the sapphire cell after sorption process, respectively.

The moles of (1) n-butane and (2) iso-butane ab(d)sorbed in the slurry (or ZIF-8 powder) are calculated as follows

$$
n_{1}=n_{t} \times z_{1}-n_{E} \times y_{1}
$$




$$
n_{2}=n_{t} \times z_{2}-n_{E} \times y_{2}
$$

where $z_{1}$ and $z_{2}$ are the mole fractions of n-butane and iso-butane of the feed gas, respectively, $y_{1}$ and $y_{2}$ are the mole fractions of n-butane and iso-butane in the gas phase of the sapphire cell in equilibrium, respectively.

Therefore, the dry-basis mole fractions of n-butane (1) and iso-butane (2) in the slurry (or ZIF-8 powder) are obtained by

$$
\begin{aligned}
& x_{1}=\frac{n_{1}}{n_{1}+n_{2}} \\
& x_{2}=\frac{n_{2}}{n_{1}+n_{2}}
\end{aligned}
$$

In the gas separation process, a separation factor is defined as $\beta$ to characterize the separation efficiency of the separation medium.

$$
\beta=\frac{x_{1} / y_{1}}{x_{2} / y_{2}}
$$

The initial gas-slurry (solid) volume ratio is determined by

$$
\varphi=\frac{22.4 \times n_{t}}{V_{l(s)}}
$$

where $V_{l}$ and $V_{S}$ are the volume of the slurry and the ZIF-8 powder, respectively. The volume of the slurry in the sapphire cell is calculated indirectly by measuring its density and mass. The volume of the ZIF-8 powder is the ratio of its mass to the skeleton density $\left(0.9244 \mathrm{~g} / \mathrm{cm}^{3}\right)$.

The sorption capacity (i.e. solubility) of n-butane (1) and iso-butane (2) in the slurry is calculated by

$$
S_{i}=\frac{n_{i}}{V_{l}}
$$

Similarly, the uptakes of n-butane (1) and iso-butane (2) in ZIF-8 powder is determined by

$$
S_{i}=\frac{n_{i}}{m}
$$

where $m$ is the mass of the ZIF-8 powder. 
The sorption coefficient of n-butane (1) and iso-butane (2) in the slurry (or ZIF-8 powder) is calculated by

$$
S_{C i}=\frac{S_{i}}{P_{E} \times y_{i}}
$$

The removal ratio of n-butane (1) $\left(R_{1}\right)$ is used to indicate the capture ability of the slurry (or ZIF-8 powder), calculated by

$$
R_{1}=\left(1-\frac{n_{E} \times y_{1}}{n_{t} \times z_{1}}\right) \times 100 \%
$$

Methods regarding the breakthrough experiment and pilot scale continuous separation experiment can be found in Supplementary methods. 
Acknowledgements: Financial support received from the National Natural Science Foundation of China (Nos. U20B6005, 22178379).

\section{References}

1. Liu $\mathrm{J}$, et al. The crucial role of reaction pressure in the reaction paths for $\mathrm{i}$-butane conversion over Zn/HZSM-5. Chem. Eng. J. 218, 1-8 (2013).

2. Müller M, Kutscherauer M, Böcklein S, Wehinger GD, Turek T, Mestl G. Modeling the selective oxidation of n-butane to maleic anhydride: From active site to industrial reactor. Catal. Today, https://doi.org/10.1016/j.cattod.2021.04.009 (2021).

3. Shao M, Hu C, Xu X, Song Y, Zhu Q. Pt/TS-1 catalysts: Effect of the platinum loading method on the dehydrogenation of n-butane. Appl. Catal. A-Gen. 621, 118194-118202 (2021).

4. Chen Z, et al. Enhanced separation of butane isomers via defect control in a fumarate/Zirconium-based metal organic framework. Langmuir 34, 14546-14551 (2018).

5. Zhou Y, et al. Carbon molecular sieving membranes for butane isomer separation. AIChE J. 65, 16749-16760 (2019).

6. Mohideen $\mathrm{MIH}$, et al. Upgrading gasoline to high octane numbers using a zeolite-like metal-organic framework molecular sieve with ana-topology. Chem. Commun. 54, 9414-9417 (2018).

7. Kuznicki SM, et al. A titanosilicate molecular sieve with adjustable pores for size-selective adsorption of molecules. Nature 412, 720-724 (2001).

8. Sircar S, Golden TC, Rao MB. Activated carbon for gas separation and storage. Carbon 34, 1-12 (1996).

9. Pham TC, Kim HS, Yoon KB. Growth of uniformly oriented silica MFI and BEA zeolite films on substrates. Science 334, 1533-1538 (2011).

10. Gascon J, Kapteijn F, Zornoza B, Sebastián V, Casado C, Coronas J. Practical approach to zeolitic membranes and coatings: state of the art, opportunities, barriers, and future perspectives. Chem. Mater. 24, 2829-2844 (2012).

11. Choi J, Jeong HK, Snyder MA, Stoeger JA, Masel RI, Tsapatsis M. Grain boundary defect elimination in a zeolite membrane by rapid thermal processing. Science 325, 590-593 (2009).

12. Wang Q, Wu A, Zhong S, Wang B, Zhou R. Highly (h0h)-oriented silicalite-1 membranes for 
butane isomer separation. J. Membrane Sci. 540, 50-59 (2017).

13. Mittal N, Bai P, Kelloway A, Siepmann JI, Daoutidis P, Tsapatsis M. A mathematical model for zeolite membrane module performance and its use for techno-economic evaluation of improved energy efficiency hybrid membrane-distillation processes for butane isomer separations. J. Membrane Sci. 520, 434-449 (2016).

14. Woo M, Choi J, Tsapatsis M. Poly(1-trimethylsilyl-1-propyne)/MFI composite membranes for butane separations. Micropor. Mesopor. Mat. 110, 330-338 (2008).

15. Liu G, et al. Mixed matrix formulations with MOF molecular sieving for key energy-intensive separations. Nat. Mater. 17, 283-289 (2018).

16. Zhang Z, Tan B, Wang P, Cui X, Xing H. Highly efficient separation of linear and branched C4 isomers with a tailor-made metal-organic framework. AIChE J. 66, 16236-16243 (2020).

17. Zeng $\mathrm{H}$, et al. Orthogonal-array dynamic molecular sieving of propylene/propane mixtures. Nature 595, 542-548 (2021).

18. Chen KJ, Madden DG, Mukherjee S, Pham T, Zaworotko MJ. Synergistic sorbent separation for one-step ethylene purification from a four-component mixture. Science 366-370, 241-246 (2019).

19. Li L, et al. Ethane/ethylene separation in a metal-organic framework with iron-peroxo sites. Science 362-365, 443-446 (2018).

20. Belmabkhout $\mathrm{Y}$, et al. Natural gas upgrading using a fluorinated MOF with tuned $\mathrm{H}_{2} \mathrm{~S}$ and $\mathrm{CO}_{2}$ adsorption selectivity. Nat. Energy 3, 1059-1066 (2018).

21. Banerjee R, et al. High-throughput synthesis of zeolitic imidazolate frameworks and application to $\mathrm{CO}_{2}$ capture. Science 319, 939-943 (2008).

22. Fan H, Peng M, Strauss I, Mundstock A, Meng H, Caro J. MOF-in-COF molecular sieving membrane for selective hydrogen separation. Nat. Commun. 12, 38-47 (2021).

23. Park KS, et al. Exceptional chemical and thermal stability of zeolitic imidazolate frameworks. $P$. Natl. Acad. Sci. USA. 103, 10186-10191 (2006).

24. Venna SR, Carreon MA. Highly Permeable Zeolite Imidazolate Framework-8 Membranes for $\mathrm{CO}_{2} / \mathrm{CH}_{4}$ Separation. J. Am. Chem. Soc. 132, $76-78$ (2010).

25. Song Q, et al. Zeolitic imidazolate framework (ZIF-8) based polymer nanocomposite membranes for gas separation. Energ. Environ. Sci. 5, 8359-8369 (2012).

26. Lee MJ, Kwon HT, Jeong H-K. High-Flux Zeolitic Imidazolate Framework Membranes for Propylene/Propane Separation by Postsynthetic Linker Exchange. Angew. Chem. Int. Edit. 57, 156-161 
(2018).

27. Pimentel BR, Lively RP. Enabling Kinetic Light Hydrocarbon Separation via Crystal Size Engineering of ZIF-8. Ind. Eng. Chem. Res. 55, 12467-12476 (2016).

28. Zhang C, Lively RP, Zhang K, Johnson JR, Karvan O, Koros WJ. Unexpected Molecular Sieving Properties of Zeolitic Imidazolate Framework-8. J. Phys. Chem. Lett. 3, 2130-2134 (2012).

29. Zhang C, Koros WJ. Tailoring the transport properties of zeolitic imidazolate frameworks by post-synthetic thermal modification. ACS Appl. Mater. Inter. 7, 23407-23411 (2015).

30. Rezaei F, Sakwa-Novak MA, Bali S, Duncanson DM, Jones CW. Shaping amine-based solid $\mathrm{CO}_{2}$ adsorbents: Effects of pelletization pressure on the physical and chemical properties. Micropor. Mesopor. Mat. 204, 34-42 (2015).

31. Brown AJ, et al. Interfacial microfluidic processing of metal-organic framework hollow fiber membranes. Science 345, $72-75$ (2014).

32. Liu H, et al. A hybrid absorption-adsorption method to efficiently capture carbon. Nat. Commun. 5, 5147-5153 (2014).

33. Li $\mathrm{H}$, et al. $\mathrm{CO}_{2}$ separation performance of zeolitic imidazolate framework-8 porous slurry in a pilot-scale packed tower. Ind. Eng. Chem. Res. 59, 6154-6163 (2020).

34. Pan $\mathrm{Y}$, et al. Separation of methane/ethylene gas mixtures efficiently by using ZIF-67/water-ethylene glycol slurry. Fluid Phase Equilibr. 414, 14-22 (2016).

35. Liu $\mathrm{H}$, et al. Tunable integration of absorption-membrane-adsorption for efficiently separating low boiling gas mixtures near normal temperature. Sci. Rep. 6, 21114-21124 (2016).

36. Chen W, et al. Separation of ethane from natural gas using porous ZIF-8/water-glycol slurry. Ind. Eng. Chem. Res. 58, 9997-10006 (2019).

37. Yang M-K, et al. Separation of IGCC syngas by using ZIF-8/dimethylacetamide slurry with high $\mathrm{CO}_{2}$ sorption capacity and sorption speed but low sorption heat. Energy 201, 117605-117614 (2020).

38. Assen $\mathrm{AH}$, et al. Ultra-tuning of the rare-earth fcu-MOF aperture size for selective molecular exclusion of branched paraffins. Angew. Chem. Int. Edit. 54, 14353-14358 (2015).

39. Li B, et al. From an equilibrium based MOF adsorbent to a kinetic selective carbon molecular sieve for paraffin/iso-paraffin separation. Chem. Commun. 52, 13897-13900 (2016).

40. Wang F, Wang W, Huang S, Teng J, Xie Z. Experiment and modeling of pure and binary adsorption of n-butane and butene-1 on ZSM-5 zeolites with different Si/Al ratios. Chinese J. Chem. 
Eng. 15, 376-386 (2007).

41. Fuertes AB, Menendez I. Separation of hydrocarbon gas mixtures using phenolic resin-based carbon membranes. Sep. Purif. Technol. 28, 29-41 (2002).

42. Hedlund J, Jareman F, Bons A-J, Anthonis M. A masking technique for high quality MFI membranes. J. Membrane Sci. 222, 163-179 (2003).

43. Hrabánek P, Zikánová A, Bernauer B, Fíla V, Kočiřík M. Butane isomer separation with composite zeolite MFI membranes. Desalination 245, 437-443 (2009).

44. Kim E, Choi J, Tsapatsis M. On defects in highly a-oriented MFI membranes. Micropor. Mesopor. Mat. 170, 1-8 (2013).

45. Lee T, Choi J, Tsapatsis M. On the performance of c-oriented MFI zeolite membranes treated by rapid thermal processing. J. Membrane Sci. 436, 79-89 (2013).

46. Stoeger JA, Choi J, Tsapatsis M. Rapid thermal processing and separation performance of columnar MFI membranes on porous stainless steel tubes. Energ. Environ. Sci. 4, 3479-3486 (2011).

47. Liu $\mathrm{H}$, et al. A porous zirconium-based metal-organic framework with the potential for the separation of butene isomers. Chem. Eur. J. 22, 14988-14997 (2016).

48. Liu J, et al. Butane isomer transport properties of 6FDA-DAM and MFI-6FDA-DAM mixed matrix membranes. J. Membrane Sci. 343, 157-163 (2009).

49. Chen G, Liu B, Li H, Yang M, Sun C, Chen W. Preparation method for zeolitic imidazolate frameworks. Patent No.: US 10,815,253 B2. (2020).

50. Hiraide S, Sakanaka Y, Kajiro H, Kawaguchi S, Miyahara MT, Tanaka H. High-throughput gas separation by flexible metal-organic frameworks with fast gating and thermal management capabilities. Nat. Commun. 11, 3867-3882 (2020). 


\section{Supplementary Files}

This is a list of supplementary files associated with this preprint. Click to download.

- SupplementaryInformation.docx 